ПЕТРОВ Вячеслав Константинович - кандидат философских наук, главный редактор сайта «Политическое образование», заместитель руководителя Школы молодого этнополитолога в РБ (vp230754@mail.ru)

ПЕТРОВА Марина Юрьевна - кандидат психологических наук, член редколлегии сайта «Политическое образование», соавтор программы экспериментального курса по подготовке оперативных сотрудников на основе компетентностного подхода в Академии ФСБ России (тр210260@ mail.ru)

\title{
О НОВОМ ПОДХОДЕ К ПОДГОТОВКЕ ПРОФЕССИОНАЛЬНЫХ АНАЛИТИКОВ
}

Аннотация. Статья посвящена ситуации с подготовкой профессиональных аналитиков, сложившейся сегодня в образовательном пространстве России. Авторы предлагают принципиально новый подход к обучению, основанный на базовых принципах, разработанных ими в результате многолетней научной, аналитической и преподавательской практики в ведущих вузах страны, преимущественно в системе ДПО. Авторы показывают, что внедрение данного подхода в виртуальную образовательную сферу (на основе компетентностного подхода и с упором на индивидуальный подход к каждому потенциальному аналитику) позволит не только создать среду активного знания для аналитиков на основе совместного решения сложных прикладных аналитических задач, но и сформировать встречное движение со стороны управленцев в их понимании профессионального мировоззрения аналитиков и ценности их аналитичеСких продуктов.

Ключевые слова: информация, аналитик, аналитика, управление, управленческое решение, управленцы, проектное мышление, индивидуальный творческий подход к обучению, совместное решение прикладных аналитических задач

$\mathrm{C}$ егодня на наших глазах мир неузнаваемо меняется и стремительно усложняется. Очередной проект глобализации (а их за всю историю человечества было несколько) после десятилетий триумфального шествия начинает пробуксовывать. Серьезным испытанием стало стремительное распространение коронавируса с малопредсказуемыми последствиями. Связность, являющаяся основой глобализации, начинает рушиться. Вновь закрываются границы; они теряют функцию фильтра, превращаясь, как это уже было ранее, в непреодолимые препятствия. Россия отстает в своем технологическом развитии от ведущих стран, и, если не предпринять решительные меры, этот процесс станет необратимым. На этом фоне резко возрастает потребность в глубокой аналитике, в понимании набирающих остроту и динамизм процессов и явлений во всем мире, ибо только на этой основе возможна выработка упреждающих управленческих решений.

На чем строить это понимание, каким критериям должны соответствовать субъекты аналитической деятельности? Как (и можно ли вообще) взращивать аналитиков, отвечающих сложности и изменчивости современной ситуации? Вопросы эти далеко не праздные.

Еще в 2013 г. созданная по инициативе Общественной палаты РФ рабочая группа в рамках работы над проектом создания Аналитического общества и разработки «Азбуки аналитики» пришла к выводу о завершении экстенсивного этапа развития аналитики, о необходимости перевода аналитической деятельности, осуществляемой различными государственными органами, негосударственными аналитическими организациями и отдельными аналитиками, на системную профессиональную основу [Будущее науки... 2013]. Еще одним важным результатом деятельности группы стал вывод о сущности нового цикла развития аналитики - о смене существующей узковедомственной парадигмы 
организации аналитической деятельности на межведомственную. Это связано с тем, что современный настоящий аналитик должен мыслить не только логично, но и широко.

По справедливому мнению авторов проекта, новый этап в развитии аналитической деятельности должен был обеспечить осуществление аналитической обработки больших массивов информации в интересах повышения качества управления и снятия множества затруднений, повсеместно возникающих в реальной действительности. Для достижения этой цели предполагалось создать общепризнанную теорию аналитической деятельности, разработать единые стандарты и технологии аналитической деятельности, а также профессиональные стандарты; организовать систему подготовки кадров аналитиков; сформировать систему аналитических центров, что в целом должно привести к появлению профессионального аналитического сообщества для осуществления масштабных общественно значимых прикладных проектов.

Все эти выводы были, безусловно, правильными и своевременными. Однако сегодня на календаре уже 2020 г., а ни по одному из этих направлений работа еще даже не началась или находится в зачаточном состоянии. Единой теории аналитической деятельности нет даже в проекте, профессиональное аналитическое сообщество не складывается (более того, часть высококлассных аналитиков фактически самоустранились, усмотрев в подходах инициаторов проекта оторванность от насущных вопросов существования аналитики), единые стандарты не разработаны, по числу и качеству отечественные аналитические центры значительно уступают мировым лидерам в этой области, и это отставание не сокращается, несмотря на некоторые достижения ${ }^{1}$.

Мы по-прежнему видим, что аналитика по большей части замещается анализом и/или интерпретацией увиденного или прочитанного. На всех уровнях констатируется крайне низкая эффективность аналитической деятельности, наличие нерешенных научных, организационных и кадровых проблем, не позволяющих выработать адекватную государственную политику в области ее развития. Недостаток компетенции нужного уровня у большей части аналитиков напрямую связан с отсутствием социального заказа и хроническим недофинансированием этой сферы деятельности со стороны государственной власти и бизнеса. Как следствие, аналитики зачастую не располагают достаточными знаниями и опытом, что не позволяет им реально чувствовать внутреннюю динамику сложных процессов, переводить ее на язык, понятный для лиц, принимающих решения. К сожалению, приходится все чаще сталкиваться с произвольным жонглированием терминами, попытками списать логические противоречия сомнительных выводов на некую специфику рассматриваемых проблем. И это касается не только начинающих аналитиков, но и людей с большим практическим опытом и научными степенями.

В конечном счете, дело дошло до того, что вновь приходится переосмысливать само понятие «аналитик» и его предназначение. Так, с одной стороны, аналитика должна присутствовать в публичном пространстве, в котором действуют законы жанра (сошел с экрана или со страниц СМИ - и ты уже никто), следовательно, такая аналитика подвержена конъюнктуре. С другой - произошло определенное «окукливание» (институционализация) аналитики: практически все государственные, экономические, общественные и т.д. структуры «обзавелись» собственными аналитиками, призванными учитывать в своей работе прежде всего специфику и функционал самих организаций, оправдывать необ-

\footnotetext{
1 Атлас российских «фабрик мысли». М.: Центр изучения кризисного общества. 2018.48 с. Доступ: https://mastersprogram.politiq.ru/wp-content/uploads/2018/11/atlas_03_046561.pdf (проверено 17.05.2020).
} 
ходимость их существования перед вышестоящими начальниками, а если речь идет о социальной сфере, медицине и образовании, - то и перед обществом. Однако такие формы институционализации аналитики оказались неспособными создать эффективную государственную систему аналитического обеспечения выработки и принятия эффективных управленческих решений как на государственном уровне, так и на уровне бизнеса.

В поисках решения этих проблем предпринимаются разные шаги. Так, некоторые специалисты прилагают усилия для возвращения к разработкам Московского методологического кружка (интеллектуально-практическая школа Георгия Петровича Щедровицкого). Но эти усилия остаются лишь попытками, в которых, кроме всего прочего, не учитывается снижение общего уровня интеллектуальной культуры, образования и знаний в обществе. Следует отметить, что сам подход - один из продуктивных, но при этом отсутствует «транслятор», который взял бы на себя функцию перевода сугубо научного (на уровне методологии) знания в практическую плоскость. Потребность же в подобного рода деятельности велика, и она будет только возрастать.

Например, вряд ли кто из лиц, принимающих решения, и их окружения удосужился прочесть глубокую книгу профессора Александра Ивановича Селиванова «Развитие общества. Наука управления будущим» [Селиванов 2016]. А ведь в ней содержатся идеи, очень важные для понимания протекающих в мире и России процессов и управления ими, конструирования будущего. Основной посыл книги заключается в том, что для прорисовывания будущего необходима идея, желательно, объединяющая, которой сегодня в России нет. Кстати, этим можно объяснить отсутствие у нас качественной научной фантастики.

В рамках устоявшихся в России схем и подходов, а также навязанных западных политологических и экономических теорий (которые в массе своей либо устарели, либо вместо понимания нагоняют наукообразный туман, либо являются не теориями вовсе, а обобщением эмпирической практики той или иной страны в ту или иную эпоху) принимать выверенные управленческие решения невозможно, т.к. велик риск совершить роковые ошибки, ведущие к непоправимым последствиям. В силу целого ряда объективных, и в первую очередь субъективных причин наука удалена из сферы управления, а где-то и самоустранилась ввиду невостребованности.

Как результат - в аналитическом сообществе произошло решительное размежевание на «сверхпрофессионалов» (концептуалистов), своеобразную крайне малочисленную касту «просвещенных» и на всех остальных, разбавленных всевозможными комментаторами и обозревателями, толпящимися в очереди на участие в бесконечных ток-шоу.

Если бы государство, бизнес и общество были удовлетворены современным уровнем аналитической деятельности, то не существовало бы такого числа всевозможных курсов и школ подготовки (обучения) аналитиков: по запросу в Яндексе мы находим 17 млн ссылок на разного рода ресурсы, а если добавить поисковые слова «аналитика» и «аналитическая деятельность» - это еще 10 млн. Просматривать все эти сайты непродуктивно, однако даже поверхностное ознакомление с содержанием материалов показывает следующее. Их абсолютное большинство рассчитано на начинающих - тех, кто хочет, чтобы аналитика стала их повседневной деятельностью, но имеет весьма смутное представление о ее содержании, при этом с обязательной специализацией (финансовый аналитик, бизнес-аналитик, аналитик данных, IT-аналитик, аналитик в сфере безопасности и т.д.). Оставшиеся ориентированы на повышение квалификации сотрудников по направлению их работодателей и носят плановый характер. И 
не факт, что после их окончания слушатель приобретет новые знания, необходимые ему для улучшения качества своей работы.

Если в учебные программы и включены вопросы, относящиеся к базовым понятиям аналитической деятельности, то часы на них сведены к минимуму, поскольку существующим и будущим работодателям это неинтересно. В 70-х гг. прошлого века в среде аналитиков (правда, тогда их так не называли; априори считалось, что если ты работаешь на компьютере, то ты уже аналитик) даже бытовала такая фраза: «засунул свинью, получил сосиски», характеризовавшая отношение среднестатистического руководителя, не желающего вникать в суть их (аналитиков) работы. Поразительно, но и сегодня подобные факты встречаются.

Так кто же такой аналитик? По мнению В.В. Летуновского, аналитик - это «человек, освоивший культуру логического мышления, опираясь на которую, он анализирует огромное разнообразие фактографического материала и синтезирует сложную причинно-следственную модель предметной области» [Летуновский 2013]. Собственно, в этом определении раскрыто то, чем должен владеть современный аналитик: анализом и синтезом на базе информационной культуры и культуры логического мышления. И этим необходимо руководствоваться при разработке программ для обучения аналитиков и создании соответствующих образовательных площадок.

Но есть еще один очень важный аспект, который не нашел отражение в определении В.В. Летуновского. Это тесная связь науки, аналитики и практики. В самом деле, аналитика является неотъемлемой частью и прикладным продолжением науки, а сама наука - это только часть аналитики, если принять во внимание прикладной характер последней, особенно при выработке управленческих значений.

Многолетний опыт научной, аналитической и педагогической деятельности позволяет авторам выделить ряд принципиальных моментов, которые необходимо учесть при выработке подходов к формированию образовательных площадок, ориентированных на взращивание высококлассных аналитиков.

Отдельные из них известны в науке и педагогике, в частности из представления знаний в контексте неклассической научной рациональности, например, в работах Майкла Полани [Полани 1985]. Знания, которые составляют основу индивидуальной картины мира аналитика, не могут быть оторванными от познающих и действующих субъектов, от их субъективных реальностей. В любом случае - соблюдается это правило или нет - частные видения мира образуют своеобразную сеть по типу Интернета. Однако при невыполнении данного условия получить адекватную интерпретацию полученных аналитиками знаний невозможно.

Еще один момент. Серьезным недостатком в подготовке аналитиков является полное отсутствие селекционной работы. Считается, что если аналитик выдает на-гора более-менее сносные материалы, то и работать над повышением уровня его подготовки незачем. Невостребованными остаются целые поколения талантливых магистров, аспирантов, молодых ученых и преподавателей. Коллективные формы обучения в плановом порядке для прохождения очередной аттестации, написание статьи (для этого же) не способствуют их росту как аналитиков. Даже возникают сомнения в том, могут ли они вообще что-либо написать, помимо научных статей.

Вместе с тем именно это является питательной средой для выращивания высокопрофессиональных аналитиков, обладающих научной методологией познания, широким кругозором, практическими навыками аналитических исследований. Отсюда и появилась идея в качестве эксперимента сформиро- 
вать образовательную площадку, исходя из следующих требований к учебному процессу.

Во-первых, индивидуальный подход к каждому слушателю с учетом знаний и опыта последних, их личностными и деловыми качествами.

Во-вторых, постоянный контакт слушателей с опытными аналитиками, имеющими богатый опыт как аналитической, так и педагогической (и, по возможности, научной) работы.

В-третьих, приобщение слушателей к неявным (личностным) знаниям и навыкам наставников с целью создания возможности для проникновения во внутренний мир носителей и творцов знаний. На определенный промежуток времени наставник становится вторым «Я» слушателя, последний как бы растворяется в нем. Взаимное познание позволяет более полно задействовать в образовательных целях творческий потенциал как наставника, так и слушателя.

В-четвертых, разъяснение слушателям важности работы с заказчиком (в ходе обучения таким заказчиком выступает сам наставник, дающий конкретные задания и оценивающий качество их выполнения). Аналитики без конкретного заказчика не бывает, она вырождается в самодеятельность, в самолюбование своим «творчеством».

B-пятых, развитие познаний слушателя в таких областях знания, как теория систем, теория управления, методы анализа, формирование и управление информационными потоками, психологические особенности отбора, накопления, обработки и представления информации и пр., в качестве обязательных дисциплин отдельного учебного модуля (самого продолжительного по времени и разнообразного по содержанию). Слушатели должны научиться на основе междисциплинарного подхода выявлять факторы среды, обусловливающие необходимость выработки управленческого воздействия, и прогнозировать их влияние на настоящее и будущее состояния системы с выработкой научно обоснованных предложений по их использованию или локализации негативных последствий и т.д.

Кроме того, будущих аналитиков планируется обучить профессионально структурировать и грамотно вербализировать информацию, компетентно оформлять конечный аналитический продукт, при этом постоянно имея в виду конкретного заказчика.

Шаги в этом направлении сегодня предпринимаются, но их недостаточно. Например, в 2016 г. журнал «Россия в глобальной политике» совместно с НИУ ВШЭ создали школу «Учи ученого», слушатели которой (молодые ученые-международники) обучаются написанию «хороших текстов в разных жанрах» 1 .

Другой пример: центр «Аналитик» открыл онлайн-школу по специальности «Аналитик политических конфликтов», в которой слушатели с использованием так называемого аналитического конструктора обучаются технологии анализа и выработки решений в конфликтных ситуациях.

Можно еще отметить Русскую аналитическую школу, созданную усилиями доктора философских наук Ю.В. Курносова ${ }^{2}$. Основной идеей провозглашена «разработка и реализация программы построения высокоэффективной самоструктурирующейся иерархической многоцелевой системы, предназначенной для подготовки высокопрофессиональных аналитиков, способных участвовать в аналитической работе в сфере государственного и муниципального управления».

Вместе с тем до настоящего времени должности руководителей департамен-

\footnotetext{
1 https://school.globalaffairs.ru (проверено 17.05.2020).

2 http://ранш.рф (проверено 17.05.2020).
} 
тов «Подготовка аналитиков» и «Фундаментальные исследования, организация и методология НИР» остаются вакантными, и это о многом говорит.

B-шестых, применение основных принципов компетентностного подхода к обучению, что позволит усилить его личностную направленность, нацелить слушателей на решение социально значимых и жизненно важных задач путем освоения новых видов и способов деятельности, сориентировать их на саморазвитие личности, активно прибегая к самоанализу, самооценке и рефлексии.

При разработке идеи площадки индивидуальной подготовки аналитиков авторы использовали опыт участия в эксперименте по подготовке оперативных сотрудников на основе компетентностного подхода, который был успешно организован на базе Академии ФСБ России в 2010-2011 гг.

Следует обратить внимание на следующий принципиально важный момент: необходимо обеспечить перенос знаний, умений и навыков из сферы науки и аналитики в плоскость выработки управленческих решений. Речь должна идти о создании среды активного знания на основе совместного решения сложных прикладных аналитических задач. При этом наставник должен уметь оперативно и профессионально входить в сферу научных и практических интересов слушателя, поскольку на первых порах именно эта сфера становится учебным полем, на котором слушатели убеждаются в эффективности предложенной методики преподавания и общения.

На подобных площадках на всех этапах - от проектирования учебного процесса до выбора модели, методов, форм, приемов и средств обучения - предполагается широко задействовать когнитивные образовательные технологии с постепенным переходом к предметно независимой индивидуально ориентированной образовательной технологии. В этих целях в процессе обучения необходимо постоянно иметь в виду природу познавательных процессов у слушателей, выработанный у них соответствующий стиль решения задач и познания мира как способа достижения результата, осуществлять диагностирование исходного и последующих состояний слушателей, фиксировать происходящие изменения для своевременной корректировки курсов.

В случае положительного результата эксперимента по созданию подобной образовательной площадки было бы целесообразно приступить к распространению накопленного опыта, созданию встречного движения со стороны управленцев в их понимании профессионального мировоззрения аналитиков. Сегодня управленцы (особенно высокопоставленные), с одной стороны, буквально купаются в многочисленных информационных потоках, становясь носителями ценной информации, с другой же - они зачастую сами не в состоянии сделать необходимые выводы. Только плодотворное сотрудничество между аналитиками и лицами, принимающими решения, позволит устранить это несоответствие.

Статья подготовлена в рамках работы Школы молодого этнополитолога в Республике Башкортостан.

\section{Список литературы}

Будущее науки: от азбучных истин к системе аналитических центров (авт. колл. под рук. В.В. Летуновского). 2013. М.: Научный эксперт. 115 с.

Летуновский В.В. 2013. От азбуки аналитики к системе аналитических центров. - Будущее науки: от азбучных истин к системе аналитических центров. М.: Научный эксперт. С. 8-27.

Полани М. 1985. Личностное знание. На пути к посткритической философии. М.: Прогресс. 344 с. 
Селиванов А.И. 2016. Развитие общества. Наука управления будущим. М.: ТД «Алгоритм». $848 \mathrm{c}$.

PETROV Vyacheslav Konstantinovich, Cand.Sci. (Philos.), Editor-in-Chief of the website «Political Education», Deputy Head of the School of Young Ethnopolitologist in Bashkortostan (vp230754@mail.ru)

PETROVA Marina Yuryevna, Cand.Sci. (Psich.), member of the website «Political Education» editorial board, co-author of the pilot course on training operational officers based on the competence approach at the Academy of the FSB of Russia (mp210260@mail.ru)

\title{
TO A NEW APPROACH TO PROFESSIONAL ANALYSTS TRAINING
}

\begin{abstract}
The article is devoted to the situation with the training of professional analysts that exists today in the educational space of Russia. The authors propose fundamentally new approach to teaching, based on the basic principles developed by the authors of the article for many years of research and analytical and teaching practice in the leading universities of the country, mainly in the system of additional professional education. The paper shows that its implementation into the virtual educational sphere (using the competency-based approach with an emphasis on an individual approach to each potential analyst) will create an active knowledge environment based on the joint solution of complex applied analytical tasks. It also will form a counter movement on the part of managers in their understanding of the professional outlook of analysts and the value of their analytical products.
\end{abstract}

Keywords: information, analyst, analytics, management, management decision, managers, project thinking, individual creative approach to learning, joint solution of applied analytical tasks 